\title{
Editorial
}

\section{Defects in Crystals}

\author{
Julita Smalc-Koziorowska
}

Institute of High Pressure Physics, Polish Academy of Sciences, Sokolowska 29/37, 01-142 Warsaw, Poland; julita@unipress.waw.pl

Received: 9 October 2020; Accepted: 9 October 2020; Published: 9 October 2020

Defects affect various properties of all kinds of crystals regardless of their sizes and applications. This special issue is devoted to experimental studies of defects in various materials. It comprises one review article and three research articles. The review by J. Shell and G. Marschick [1] presents an overview of the time-differential perturbed angular correlation (TDPAC) measurements of ferroic and multiferroic materials. TDPAC is a very sensitive nuclear solid-state spectroscopy technique that is based on the interaction between electrical and magnetic fields with the nuclear moment. In this review article, TDPAC is used to probe the point defects and various mechanisms governing the electronic and magnetic interactions in chalcogenide spinels, lead titanate, lead zirconate, and bismuth ferrite.

The TDPAC method was also used by J. Shell et al. [2] in a study of point defects in Cd-doped $\mathrm{SnO}_{2}$. The results of this research show the evolution of incorporating Cd dopants into the crystal lattice during annealing at various temperatures.

The structural transformation and formation of defects in crystals irradiated with X-ray is in the focus of the studies performed by Y. Kohzuki and T. Ohgaku [3]. In their research article, they present results of the investigations of the luminescence properties of $\mathrm{KCl}$ crystals doped with $\mathrm{Eu}^{2+}$ after X-ray irradiation.

The research article by M. Hou et al. [4] discusses the influence of magnetic fields on the dislocation density, residual stress, and hardness of $\mathrm{Cr}_{4} \mathrm{Mo}_{4} \mathrm{~V}$ steel. The interesting outcome of this work is that the dislocation density and compressive residual stress in this material decrease in the presence of low intensity magnetic fields, and the opposite effect was observed for higher magnitude magnetic fields.

Funding: This research received no external funding.

Conflicts of Interest: The author declare no conflict of interest.

\section{References}

1. Schell, J.; Marschick, G. TDPAC Studies of Local Defects and Phenomena in Ferroics and Multiferroics. Crystals 2019, 9, 611. [CrossRef]

2. Schell, J.; Dang, T.T.; Carbonari, A.W. Incorporation of Cd-Doping in $\mathrm{SnO}_{2}$. Crystals 2020, 10, 35. [CrossRef]

3. Kohzuki, Y.; Ohgaku, T. Study on Luminescence of $\mathrm{KCl}: \mathrm{Eu}^{2+}$ Crystals after X-ray Irradiation at Room Temperature. Crystals 2019, 9, 331. [CrossRef]

4. Hou, M.; Li, K.; Li, X.; Zhang, X.; Rui, S.; Wu, Y.; Cai, Z. Effects of Pulsed Magnetic Fields of Different Intensities on Dislocation Density, Residual Stress, and Hardness of $\mathrm{Cr}_{4} \mathrm{Mo}_{4} \mathrm{~V}$ Steel. Crystals 2020, 10, 115. [CrossRef]

(C) 2020 by the author. Licensee MDPI, Basel, Switzerland. This article is an open access article distributed under the terms and conditions of the Creative Commons Attribution (CC BY) license (http://creativecommons.org/licenses/by/4.0/). 